\title{
Odległe wyniki replantacji rąk
}

\section{Late outcomes after hand replantation}

\author{
Andrzej Żyluk ${ }^{\bowtie}$, Ada Owczarska
}

Pomorski Uniwersytet Medyczny w Szczecinie, Klinika Chirurgii Ogólnej i Chirurgii Ręki, ul. Unii Lubelskiej 1, 71-252 Szczecin Pomeranian Medical University in Szczecin, Department of General and Hand Surgery

$\triangle$ azyluk@hotmail.com

\begin{abstract}
Introduction: The objective of this study was to evaluate functional outcomes in patients who underwent successful replantation of amputated hands at least 5 years ago in Department of General and Hand Surgery of the Pomeranian Medical University in Szczecin (Poland).

Materials and methods: 54 patients who underwent successful replantation of amputated hands or fingers were identified. These patients were mailed a set of questionnaires asking for hand function (DASH questionnaire), quality of life (SF-36), cold intolerance, and return to work. 22 completed questionnaires were returned ( $41 \%$ response rate), and these data were the subject of the analysis. The study group also comprised 5 patients who were examined in the hospital. The group consisted of 22 patients, 20 men and 2 women, with a mean age of 43 years (range 20-82), who had hand or finger replantation a mean of 6.5 years before the assessment (range 5-7). Most patients had amputation of the metacarpus $(n=9)$, followed by fingers II-V ( $n=8)$, wrist $(\mathrm{n}=2)$, thumb $(\mathrm{n}=2)$ and forearm $(\mathrm{n}=1)$. The cause of amputation was circular saw in 15 cases $(68 \%)$ followed by industrial or agriculture machinery.
\end{abstract}

Results: The mean DASH score for the whole group was 23 (range 2-74), indicating on average mild dysfunction of the replanted hands. Ten (45\%) patients regained very good function (DASH $<20), 7(32 \%)$ showed mild dysfunction (DASH 21-40), and 5 had greater disability (DASH $>40)$. The functional outcomes were best in patients following wrist and thumb replantation (DASH 4), less favourable in patients after finger II-V replantation (DASH 16), and poorest in patients after metacarpus and forearm replantation (DASH 33). The mean score in the physical subscale of the SF-36 questionnaire was 61, indicating good quality of life. For the mental SF- 36 subscale the mean score was 58 , indicating moderate quality of life. Twenty patients complained of troublesome symptoms of cold intolerance. Twelve (54\%) patients returned to previously performed work.

Conclusion: The results of this study show that most patients regained good function of replanted hands, allowing them good functioning in a daily life and a return to work in some of them.

Keywords: hand replantation; functional outcomes; quality of life.

\section{ABSTRAKT}

Wstęp: Celem pracy była ocena wyników czynnościowych u pacjentów, którym wykonano replantacje rąk w Klinice Chirurgii Ogólnej i Chirurgii Ręki Pomorskiego Uniwersytetu Medycznego w Szczecinie, co najmniej przed 5 laty.

Materiały i metody: Zebrano dane 54 pacjentów, którym w latach 2009-2012 wykonano udaną replantację amputowanych rąk lub palców. Do tych osób wysłano zestaw kwestionariuszy z pytaniami o sprawność kończyny (kwestionariusz DASH), poziom jakości życia (kwestionariusz SF-36), objawy nadwrażliwości na ochłodzenie i powrót do pracy. Otrzymano 22 wypełnione kwestionariusze ( $41 \%$ wysłanych) i te dane były przedmiotem analizy. W tej grupie było także 5 pacjentów, których zbadano bezpośrednio w szpitalu. Podstawę oceny stanowiły wyniki uzyskane od 22 pacjentów, 20 mężczyzn i 2 kobiet w średniej wieku 43 lat (zakres 20-82), którzy mieli wykonaną replantację ręki/ palców średnio 6,5 roku przed badaniem (zakres 5-7). Najwięcej pacjentów miało replantację na wysokości śródręcza $(n=9)$, palców II-V ( $n=8)$, nadgarstka $(n=2)$, kciuka $(n=2)$ i przedramienia $(\mathrm{n}=1)$. Przyczyną urazu w $15(68 \%)$ przypadkach była piła tarczowa, a w pozostałych maszyny przemysłowe i rolnicze.
Wyniki: Średnia punktacja kwestionariusza DASH dla całej grupy wynosiła 23 (zakres 2-74), co wskazywało na średnio niewielkie upośledzenie czynności replantowanej ręki. Bardzo dobrą czynność ręki miało 10 (45\%) pacjentów (DASH <20), 7 (32\%) niewielkie upośledzenie (DASH 21-40), a 5 (23\%) - znaczne upośledzenie (DASH >40). Najlepsze wyniki pod względem czynnościowym wykazywali pacjenci po replantacjach nadgarstka i kciuka (DASH 4), nieco gorsze po replantacjach palców II-V (DASH 16), a najgorsze po replantacji śródręcza i przedramienia (DASH 33). Średnia punktacja kwestionariusza SF-36 w domenie fizycznej wynosiła 61 pkt (dobra jakość życia), a w sferze mentalnej 58 pkt (średnia jakość życia). Dość dokuczliwe objawy nietolerancji zimna miało 20 (91\%) pacjentów. Do wcześniej wykonywanej pracy wróciło 12 (54\%) osób.

Wniosek: Uzyskane wyniki wskazują, że większości pacjentów udało się uzyskać dobrą czynność replantowanych rąk, pozwalającą na dobre funkcjonowanie w życiu codziennym, a części na powrót do pracy.

Słowa kluczowe: replantacja ręki; wyniki czynnościowe; jakość życia. 


\section{WSTĘP}

Skuteczna replantacja ręki jest zawsze bardzo pozytywnym wydarzeniem dla okaleczonego pacjenta $[1,2]$. Przeciwwskazania do replantacji kończyny są ograniczone w zasadzie do przypadków urazu wielonarządowego, w którym intensywne leczenie innych, zagrażających życiu obrażeń stanowi priorytet, oraz czas od amputacji przekraczający 10 godz., przy nieodpowiednim schłodzeniu kończyny w trakcie transportu (nie dotyczy to palców, które można replantować nawet po 24 godz.). Mechanizm urazu i stopień uszkodzenia amputowanej kończyny rzadko stanowią powód odstąpienia od próby replantacji $[3,4,5]$. Jednak wyniki czynnościowe tych operacji nie zawsze są zadowalające i w części przypadków pacjenci nie odzyskują sprawności w zakresie umożliwiającym powrót do pracy i/lub normalnej aktywności życiowej [6, 7]. Wyniki leczenia pacjentów po replantacji rąk od poziomu śródręcza i amputacji wielu palców są rzadziej publikowane niż wyniki po replantacji pojedynczych palców i kciuków. Także metodyka oceny wyników często budzi zastrzeżenia [8]: tylko w niektórych pracach oceniana jest czynność ręki i jakość życia za pomocą standaryzowanych kwestionariuszy [7, 9].

Celem pracy była ocena wyników czynnościowych u pacjentów, którym wykonano replantacje rąk i palców i u których okres obserwacji wynosił co najmniej 5 lat. Po takim czasie zwykle pacjent zakończył już leczenie chirurgiczne, rehabilitację i na tyle przyzwyczaił się do stanu swojej odzyskanej kończyny, żeby wynik leczenia można było uznać za ostateczny.

\section{MATERIAŁY I METODY}

Zebrano dane 54 pacjentów, którym w Klinice Chirurgii Ogólnej i Chirurgii Ręki Pomorskiego Uniwersytetu Medycznego w Szczecinie w latach 2009-2012 wykonano udaną replantację amputowanych rąk lub palców. Na podstawie dokumentacji medycznej określono poziom i rodzaj amputacji, a także narzędzie raniące. Do tych osób wysłano zestaw kwestionariuszy z pytaniami dotyczącymi:

- sprawności kończyny (kwestionariusz DASH),

- poziomu jakości życia (kwestionariusz SF-36),

- objawów nadwrażliwości na ochłodzenie,

- powrotu do pracy.

Otrzymano 22 wypełnione kwestionariusze (41\% wysłanych) i te dane były przedmiotem analizy. Dodatkowo 5 z tych chorych stawiło się do kontroli osobiście i u nich zmierzono całkowity zakres ruchomości palców (goniometrem) i siłę chwytu globalnego (dynamometrem Jamar). Całą grupę stanowiło 20 mężczyzn i 2 kobiety o średniej wieku wynoszącej 43 lata (zakres 20-82), którzy mieli wykonaną replantacje ręki/palców średnio 6,5 (zakres 5-7) roku przed badaniem. Najwięcej pacjentów miało replantację na wysokości śródręcza ( $\mathrm{n}=9)$ ), palców II-V ( $\mathrm{n}=8)$, nadgarstka $(\mathrm{n}=2)$, kciuka $(n=2)$ i przedramienia $(n=1)$. Amputacja dotyczyła kończyny dominującej (prawej) u 12 osób, a niedominującej (lewej) u 10. Całkowicie amputowane ręce lub palce miało 19 (86\%) chorych, a 3 (14\%) - prawie całkowicie. Przyczyną urazu w 15 (68\%) przypadkach była piła tarczowa, a w pozostałych maszyny przemysłowe i rolnicze. Czas od urazu do rozpoczęcia operacji (okres niedokrwienia) wynosił 3-10 (średnia 4,5) godz.

Operacje wykonywano w znieczuleniu przewodowym lub ogólnym z użyciem lup i niedokrwienia kończyny. Zespół tworzyło dwóch chirurgów, z których najczęściej obaj byli wyszkoleni mikrochirurgicznie. Typowo rozpoczynano od jednoczesnego preparowania naczyń, nerwów i ścięgien na kikucie oraz części amputowanej, wykonywano skrócenie kości i przystępowano do zespolenia. W 21 przypadkach zespolenie kostne wykonywano za pomocą drutów $\mathrm{K}$, a u jednego chorego $\mathrm{z}$ amputacją przedramienia użyto płytek tytanowych. Kolejność dalszych rekonstrukcji zależała od sytuacji: najczęściej najpierw wykonywano zszycia ścięgien, potem zespolenia naczyń, a na końcu, po zwolnieniu opaski zszywano nerwy i mięśnie. W 8 przypadkach amputacji 4 palców u 3 chorych skutecznie przyszyto 2 palce, a u 5 - jeden z amputowanych palców. Jako zasadę przyjęto nieprzekraczanie 3 godz. czasu opaski uciskowej. Czas trwania operacji wynosił 2-6 godz.

\section{OPIS KWESTIONARIUSZY UŻYWANYCH W PRACY}

Kwestionariusz DASH (Disability of Arm, Shoulder and Hand) jest 30-punktowym testem samooceny funkcji kończyny górnej określającym stopień jej sprawności. Pierwsze 23 pytania dotyczą sprawności kończyny górnej w wykonywaniu codziennych czynności, a pozostałe 7 - odczuwanych dolegliwości. Każde z pytań jest oceniane przez badanego w skali 1-5, przy czym 1 oznacza brak dolegliwości lub wykonywanie danej czynności bez trudności, a 5 - stałe występowanie dolegliwości lub niemożność wykonania danej czynności. Zakres punktacji wynosi 0-100, przy czym mniejsza liczba punktów oznacza ogólną lepszą, a większa - gorszą sprawność kończyny górnej. Zakres 0-20 oznacza pełną sprawność, zakres 21-40 niewielką, 41-60 - umiarkowaną, a >60 - znaczną niesprawność kończyny (kalectwo).

Kwestionariusz SF-36 (36-Item Short-Form Health Survey) jest instrumentem zaprojektowanym do oceny jakości życia. Składa się z 36 pytań zgrupowanych w 8 kategoriach, które pozwalają określić 8 wymiarów jakości życia. Wyniki oceny podaje się zwykle w postaci punktacji 2 domen: fizycznej (4 kategorie) i mentalnej (4 kategorie). Odpowiedzi na każde pytanie mają przypisane wagi, przyjmując wartości 0-100. Następnie w każdej z 8 kategorii uzyskuje się wynik w postaci 100-punktowej skali. Wyniki można podawać w każdej z 8 kategorii osobno lub w domenach. Wyższa punktacja kwestionariusza SF-36 oznacza lepszą jakość życia, a niższa - gorszą. Zakres 84-100 oznacza bardzo dobrą, 61-83 - dobrą, 25-60 - mierną, a <25 - złą jakość życia.

\section{WYNIKI}

Oceniono wyniki leczenia 22 pacjentów, u których wykonano replantację ręki lub palców średnio 6,5 roku przed badaniem 
TABELA 1. Wyniki badanych parametrów w grupie 22 pacjentów po średnio 6,5 roku od replantacji ręki lub palców

\begin{tabular}{lcc}
\multicolumn{1}{c}{ Badany parametr } & Średnia & Zakres \\
\hline Punktacja kwestionariusza DASH & 23 & $2-74$ \\
\hline Punktacja SF-36, domena fizyczna & 61 & $22-91$ \\
\hline Punktacja SF-36, domena mentalna & 58 & $16-96$ \\
\hline Nadwrażliwość na oziębienie & 20 & $91 \%$ \\
\hline Powrót do pracy & 12 & $54 \%$ \\
\hline
\end{tabular}

TABELA 2. Wyniki badanych parametrów w grupie 5 pacjentów po średnio 6,5 roku od replantacji ręki lub palców, którzy osobiście zgłosili się na badania

\begin{tabular}{lccc}
\multicolumn{1}{c}{ Badany parametr } & Średnia & Zakres & $\%$ \\
\hline Całkowita ruchomość palców $\left(^{\circ}\right)$ & 210 & $70-270$ & 78 \\
\hline Siła chwytu globalnego (kG) & 15 & $5-28$ & 34 \\
\hline Punktacja kwestionariusza DASH & 21 & $10-34$ & - \\
\hline Punktacja SF-36 (obie domeny) & 74 & $68-85$ & - \\
\hline Nadwrażliwość na oziębienie & 5 & - & 100 \\
\hline Powrót do pracy & 3 & - & 60 \\
\hline
\end{tabular}

Wartości procentowe ruchomości palców i siły chwytu odnoszą się do zdrowej ręki

kontrolnym. Wyniki przedstawiono w tabeli 1. Średnia punktacja kwestionariusza DASH dla całej grupy wynosiła 23 (zakres 2-74), co wskazywało na średnio niewielkie upośledzenie czynności replantowanej ręki. Bardzo dobrą czynność ręki miało 10 (45\%) pacjentów (DASH <20), 7 (32\%) nieznacznie upośledzoną (DASH 21-40), a 5 (23\%) umiarkowanie i znacznie upośledzoną (DASH >40). Najlepsze wyniki pod względem czynnościowym wykazywali 4 pacjenci po replantacjach nadgarstka i kciuka (średnia DASH 4), nieco gorsze po replantacjach palców II-V (średnia DASH 16), a najgorsze po replantacji śródręcza i przedramienia (średnia DASH 33).

Średnia punktacja kwestionariusza SF-36 w domenie fizycznej wynosiła 61 pkt (dobra, granicząca z bardzo dobrą jakość życia), a w sferze mentalnej 58 pkt (mierna, granicząca z dobrą jakość życia). Dość dokuczliwe objawy nadwrażliwości na zimno, które manifestowały się głównie uczuciem marznięcia kończyny w chłodnych porach roku, bólem i zasinieniem przy ekspozycji na zimno, miało 20 (91\%) pacjentów. Większość z tych osób nosiła rękawiczki na replantowanej ręce od jesieni do wiosny. Do pracy wróciło 12 (54\%) pacjentów, z czego 7 do wcześniej wykonywanej.

W grupie 5 osób zbadanych bezpośrednio całkowity zakres ruchomości palców wynosił średnio $210^{\circ}$ (zakres 70-270), co stanowi średnio 78\% zakresu normalnego ruchomości. Siła chwytu globalnego wynosiła średnio $15 \mathrm{kG}$ (zakres 5-28), co stanowiło 34\% siły zdrowej ręki. Pacjenci ci uzyskali lepsze niż w całej grupie średnie wartości punktacji DASH i SF-36 (tab. 2).

Dwóch pacjentów - jeden po replantacji śródręcza, drugi po replantacji przedramienia - miało najgorsze wyniki czynnościowe (DASH 66 i 74), co świadczyło o znacznym upośledzeniu czynności ręki. W obu przypadkach amputacja dotyczyła kończyny dominującej. Pacjenci ci mieli także najsłabsze wyniki w ocenie jakości życia - w domenie fizycznej 22 i 31 pkt (zła i mierna na granicy złej), a w mentalnej - 16 i 20 pkt (zła jakość życia).

U 17 (77\%) chorych z analizowanej grupy wykonano przynajmniej jedną operację dla poprawienia czynności replantowanej ręki: tenolizę ścięgien zginaczy lub prostowników, dwuetapową rekonstrukcję ścięgien zginaczy, wtórne zszycie nerwu i odtworzenie opozycji kciuka. Wszyscy chorzy byli zadowoleni z operacji przyszycia utraconej kończyny, nawet ci, którzy nie odzyskali zadowalającej sprawności. Sama jej obecność była istotnym czynnikiem poprawiającym ich ogólną samoocenę (body image). Nawet dwaj pacjenci, którzy uzyskali najsłabsze wyniki czynnościowe i źle oceniali swoją jakość życia, deklarowali zadowolenie z powodu przyszycia amputowanej kończyny, uważając, że z kikutem ręki ich życie byłoby jeszcze trudniejsze.

Wyniki leczenia pacjentów po amputacjach rąk zawarto na rycinach 1-4.

\section{OMÓWIENIE}

Przedstawione w pracy wyniki są interesujące ze względu na długi okres obserwacji. W przypadkach replantacji kończyn kilkuletni okres obserwacji jest niezbędny do ostatecznej oceny wyniku leczenia z kilku powodów. Większość pacjentów w ciągu pierwszego roku wymaga dodatkowych operacji, aby naprawić defekty anatomiczne lub czynnościowe. Osiągnięcie optymalnej sprawności ręki może wymagać nawet 2 lat usprawniania, a adaptacja do posługiwania się mniej sprawną kończyną może trwać nawet jeszcze dłużej. Dlatego jako optymalny okres do oceny wyniku leczenia przyjmuje się 5 lat od urazu $[1,4,7]$. W piśmiennictwie można znaleźć kilka prac, w których opisywane są wyniki odległe po replantacjach kończyn górnych.

We wcześniejszej pracy własnej oceniano wyniki czynnościowe po replantacjach 19 rąk amputowanych od poziomu śródręcza do ramienia. Po średnio 2,5 roku od urazu ruchomość czynna palców wynosiła średnio $116^{\circ}$ (zakres 26-224), siła chwytu globalnego średnio 8,3 kG (zakres 2-12 kG), a sprawność ręki w skali DASH średnio 61 pkt. Lepsze wyniki czynnościowe uzyskano po amputacjach śródręcza i nadgarstka niż przedramienia i ramienia [9]. Prezentowe obecnie wyniki są lepsze pod względem odzyskanej czynności kończyny, ale zarówno materiał oceniany w tych dwóch pracach jest różny (w obecnej jest 10 pacjentów po amputacjach palców i kciuków), jak i czas obserwacji (w obecnej pracy ponad 2-krotnie dłuższy). Oba te czynniki mogły mieć istotny wpływ na uzyskane wyniki.

Jabłecki i wsp. przedstawili wyniki replantacji kończyn górnych amputowanych na różnych poziomach u 328 chorych [8]. Jest to jeden z największych materiałów opublikowanych na świecie obejmujący operacje wykonane w ciągu ponad 25 lat. Nie sprecyzowano czasu wykonywania badań kontrolnych, a poszczególne wyniki podano w klasyfikacji Chena (tab. 3) [10]: 213 (65\%) osób uzyskało I i IIº a 115 (35\%) III i IV ${ }^{\circ}[8]$. 

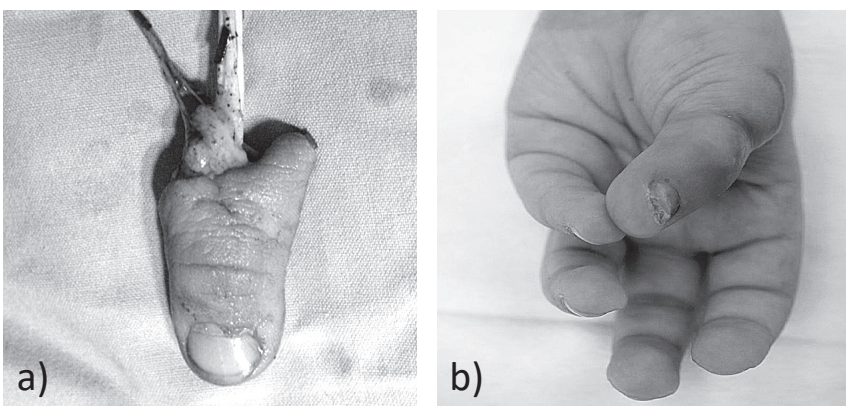

RYCINA 1. Amputacja awulsyjna kciuka (a) oraz wynik leczenia po 2 latach od urazu (b)
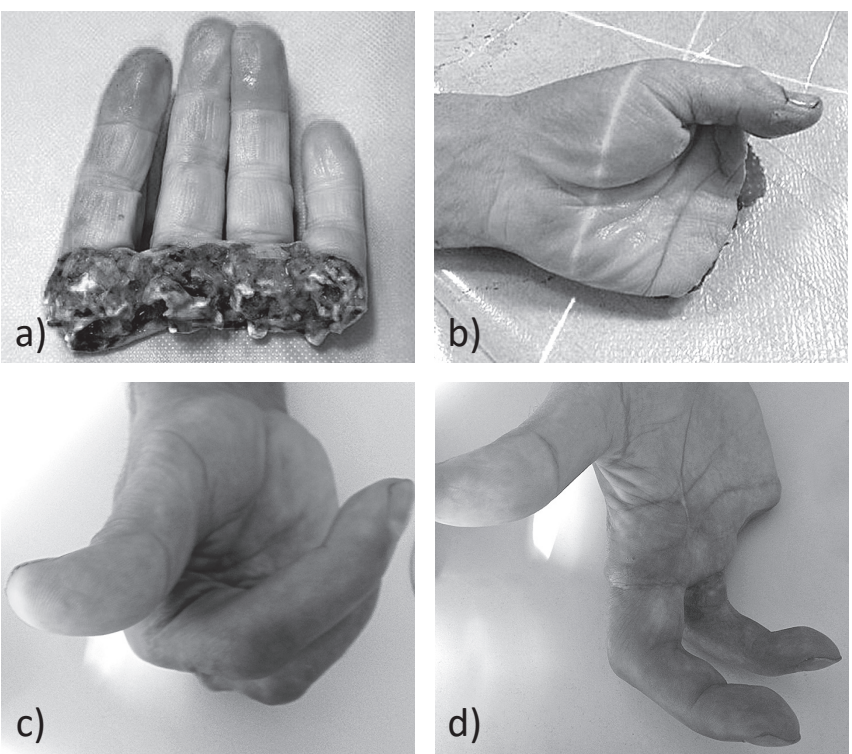

RYCINA 2. Amputat śródręcza (a) oraz kikut śródręcza (b) u 82-letniego pacjenta, a także wynik leczenia po 5 latach od urazu - zgięcie palców (c) i wyprost palców (d)
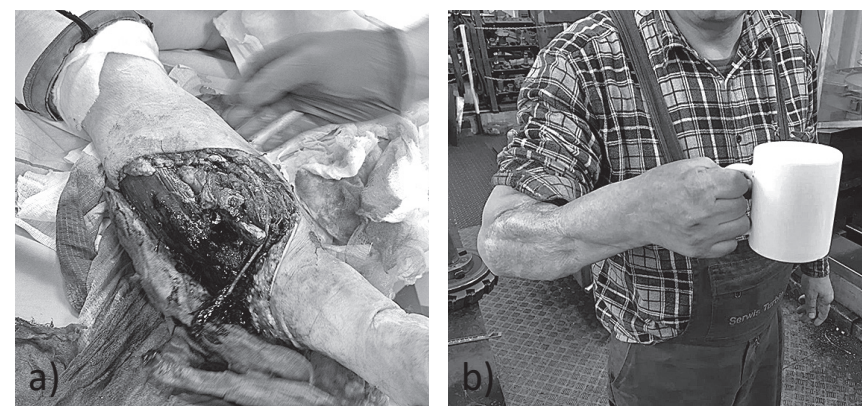

RYCINA 3. Prawie całkowita amputacja zmiażdżeniowa przedramienia (a) oraz wynik leczenia po 5 latach - zdjęcie w zakładzie pracy, gdzie miał miejsce wypadek (b)
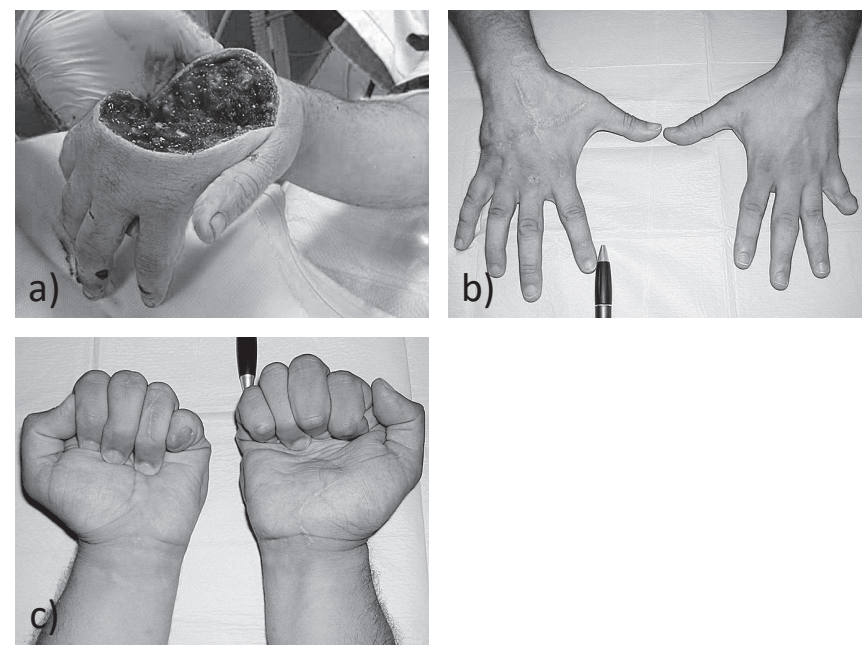

RYCINA 4. Prawie całkowita gilotynowa amputacja śródręcza (a), a także wynik leczenia po 5 latach od urazu - pełen wyprost palców (b) oraz pełne zgięcie palców (c)

TABELA 3. Klasyfikacja Chena sprawności ręki po replantacji [10]

\begin{tabular}{|c|c|c|c|c|c|}
\hline Stopień & Powrót do pracy & AROM* & Czucie & Nietolerancja zimna & Sita chwytu \\
\hline I & ten sam zawód & $>60 \%$ & norma & nie & $4-5$ \\
\hline II & inny zawód & $40-60 \%$ & zadowalające & nie & $3-4$ \\
\hline III & nie wrócit & $30-40 \%$ & ochronne & tak & śladowa \\
\hline
\end{tabular}

*AROM - zakres ruchów czynnych palców (active range of motion) wyrażony jako procent zakresu ruchów czynnych palców zdrowej ręki

Graham i wsp. ocenili wyniki czynnościowe replantacji 22 kończyn amputowanych od poziomu nadgarstka po średnio 4 latach od urazu. Do oceny czynnościowej użyto testu Carrola, w którym ocenia się sprawność ręki w wykonywaniu 33 zadań z użyciem dołączonego do testu zestawu przedmiotów. Zadania oceniały sprawność w chwytaniu obiektów o różnym kształcie i rozmiarach z wykorzystaniem ruchów odwracania i nawracania przedramienia. Siła, czucie i zakres ruchomości w stawach nie były bezpośrednio oceniane. W 8 (36\%) przypadkach sprawność replantowanej kończyny oceniono jako dobrą, a w 14 (64\%) jako niezadowalającą [11].

W innej pracy oceniono wyniki czynnościowe replantacji 6 rąk odciętych na poziomie od śródręcza do dalszej części przedramienia. W badaniu po średnio 4,5 roku od urazu pełen zakres ruchów czynnych palców uzyskało 4 chorych, a siła chwytu globalnego wynosiła średnio 50\% siły zdrowej ręki. W klasyfikacji Chena uzyskano 1 wynik $I^{\circ}, 3-$ II $^{\circ}$ i 1 - III ${ }^{\circ}[12]$.

W żadnym z wyżej cytowanych artykułów nie badano jakości życia chorych po replantacjach rąk, zatem zaletą niniejszej pracy jest ocena właśnie tego aspektu. Wyniki wskazują, że mimo przeżycia dramatycznego urazu jakość życia pacjentów z badanej grupy była stosunkowo dobra zarówno w sferze funkcjonowania fizycznego, jak i w sferze mentalnej. Za zadowalający należy także uznać fakt, że ponad połowa osób po tak okaleczającym urazie powróciła do pracy. 
Do wad prezentowanej pracy można zaliczyć niski odsetek (41\%) pacjentów, których udało się zbadać, w stosunku do wszystkich zoperowanych. Jest to typowe zjawisko obserwowane przez autorów także przy wykonywaniu innych badań, na które nie ma bezpośredniego wpływu. Po zakończeniu leczenia większość pacjentów nie jest zainteresowana badaniami kontrolnymi wykonywanymi w celach naukowych, które nie będą miały bezpośredniego wpływu na poprawę ich stanu zdrowia. Inną wadą pracy jest metodyka badań oparta głównie na ocenie „na odległość”, za pomocą wysyłanych pocztą kwestionariuszy. Nasze wcześniejsze doświadczenia wskazują, że pacjenci nie zawsze poprawnie interpretują pytania kwestionariuszy, szczególnie stosunkowo złożonego testu SF-36 [13]. Ponadto ocena bezpośrednia parametrów czynnościowych (zakresu ruchomości i siły chwytu) ma istotne znaczenie we wszechstronnej ocenie wyniku leczenia. Taka formuła jest jednak coraz częściej stosowana w badaniach naukowych, także ze względu na niechęć pacjentów do stawiania się osobiście do kontroli, szczególnie jeżeli mieszkają daleko od miejsca, w którym byli leczeni.

W podsumowaniu uzyskanych w niniejszej pracy wyników można stwierdzić, że w większości przypadków długotrwała i pracochłonna operacja pozwoliła na odzyskanie zadowalającej sprawnościowo kończyny, pozwalającej na dobre funkcjonowanie w życiu codziennym. Zarówno wyniki własne, jak i opinie z piśmiennictwa wskazują na zasadność podejmowania prób replantacji utraconej kończyny, niezależnie od mechanizmu urazu i stopnia jej uszkodzenia, jeżeli tylko stan ogólny chorego pozwala na bezpieczne jej wykonanie $[1,3,6,7]$.

\section{PIŚMIENNICTWO}

1. Prucz RB, Friedrich JB. Upper extremity replantation: current concepts. Plast Reconstr Surg 2014;133:333-42.

2. Friedrich JB, Poppler LH, Mack CD, Rivara FP, Levin LS, Klein MB. Epidemiology of upper extremity replantation surgery in the United States. J Hand Surg [Am] 2011;36(11):1835-40. doi: 10.1016/j.jhsa.2011.08.002.

3. Żyluk A, Jabłecki J, Romanowski L, Mazur A. Raport z trzyletniej działalności Serwisu Replantacyjnego dla amputacji rąk w Polsce. Pol Przegl Chir 2012;84:1022-34.

4. Gulgonen A, Ozer K. Long-term results of major upper extremity replantations. J Hand Surg 2012;37E:223-32.

5. Lindfors N, Raatikainen T. Incidence, epidemiology and operative outcome of replantation and revascularization of injury to the upper limb. Scand J Plast Reconstr Surg Hand Surg 2010;44:44-9.

6. Stanger K, Horch RE, Dragu A. Severe mutilating injuries with complex macroamputations of the upper extremity - is it worth the effort? World J Emerg Surg 2015;10:30. doi: 10.1186/s13017-015-0025-6.

7. Mahajan RK, Mittal S. Functional outcome of patients undergoing replantation of hand at wrist level-7 year experience. Indian J Plast Surg 2013;46(3):555-60. doi: 10.4103/0970-0358.122018.

8. Jabłecki J, Maj A, Kocięba R. Własne doświadczenia w zakresie usprawniania kończyn po replantacji na wysokości nadgarstka. Chir Narządów Ruchu Ortop Pol 1999;64:603-8.

9. Żyluk A, Walaszek I. Ocena wyników replantacji kończyn górnych. Chir Narządów Ruchu Ortop Pol 2007;72:165-73.

10. Chen Z, Yang D, Yu Z. Extremity replantation. World Surg 1978;2: 513-21.

11. Graham B, Adkins P, Tsai TM, Firrel J, Breidenbach W. Major replantation versus revision amputation and prosthetic fitting in the upper extremity: a late functional study. J Hand Surg 1998;23A:783-91.

12. Hegazi M. Hand and distal forearm replantation - immediate and longterm follow-up. Hand Surg 2000;5:119-24.

13. Żyluk A, Skała K, Szlosser Z. A comparison of outcomes of K-wire vs plate fixation for distal radial fractures with regard to patients' quality of life. Acta Orthop Belg 2017 [in press]. 